\title{
Spectrum of congenital heart defects and extracardiac malformations associated with chromosomal abnormalities: results of a seven year necropsy study
}

\author{
C Tennstedt, R Chaoui, H Körner, M Dietel
}

Department of Pathology, Charité Hospital of the Humboldt University, Berlin, Germany C Tennstedt

Unit of Prenatal Diagnosis and Therapy, Department of Gynaecology and Obstetrics, Charité Hospital

R Chaoui

Institute of Medical Genetics, Charité Hospital

H Körner

Department of Pathology, Charité Hospital M Dietel

Correspondence to: Dr C Tennstedt, Department of Pathology, Charite Hospital of the Humboldt University, Schumannstrasse 20/21, D 10117 Berlin, Germany.

Accepted for publication 16 February 1999

\begin{abstract}
Objective-To analyse the spectrum of congenital heart malformations, the frequency of extracardiac malformations, and the proportion of chromosome aberrations among fetuses sent for necropsy. Material-Necropsies were performed on 815 fetuses -448 induced abortions (55\%), 220 spontaneous abortions (27\%), and 147 stillbirths $(18 \%)$-during a seven year period (1991-97) in the department of pathology of the Charité Medical Centre in Berlin. A congenital heart defect was identified in 129 cases (16\%). For all 129 fetuses, karyotyping and an ultrasound examination had been performed.

Results-Congenital heart defects were present in $22 \%$ of induced abortions (99 cases), $9 \%$ of spontaneous abortions (20 cases), and $7 \%$ of stillbirths (10 cases). The heart malformations were classified into $\mathbf{1 3}$ categories. A fetus with more than one defect was included only in the category of the most serious defect. The malformations in order of frequency were: ventricular septal defect (VSD) (28\%), atrioventricular septal defect (AVSD) (16\%), hypoplastic left heart (HLH) (16\%), double outlet right ventricle (DORV) (12\%), coarctation of the aorta (CoA) $(6 \%)$, transposition of the great arteries (TGA) (4\%), aortic valve stenosis (AoVS) (4\%), tetralogy of Fallot (TOF) (3\%), truncus arteriosus communis (TAC) (3\%), pulmonary valve stenosis/ pulmonary valve atresia (PaVS/PaVA) (3\%), tricuspid atresia (TA) (3\%), single ventricle (SV) $(1.5 \%)$, and atrial septal defect (ASD) $(0.5 \%)$. The most common congenital heart defects were VSD, AVSD, HLH, and DORV, which made up $72 \%$ of all the cases. In 11 cases the heart defect was isolated (no other cardiovascular or extracardiac malformations present), 85 cases $(66 \%)$ were associated with additional cardiac malformations, 85 cases $(66 \%)$ were associated with extracardiac malformations, and chromosome anomalies were detected in 43 cases (33\%). Conclusions-Fetal congenital heart malformations are common. These defects are often associated with other cardiovascular and extracardiac malformations, as well as with chromosome anomalies. Complex heart defects such as AVSD, HLH, and DORV are frequent in fetuses,
\end{abstract}

as they often lead to spontaneous abortion or stillbirth or, after prenatal diagnosis, to deliberate termination of pregnancy. (Heart 1999;82:34-39)

Keywords: congenital heart defects; extracardiac malformations; chromosomal abnormalities; necropsy examination

Congenital heart defects, which make up about $1 \%$ of human malformations, are among the most common malformations in fetuses. Because of their poor prognosis they contribute significantly to infant mortality. Various epidemiological studies have shown that in liveborn infants the incidence of congenital heart defects is between four and eight per $1000^{1-4}$; in stillborn infants the incidence is 10 times that of live births. ${ }^{56}$ The prenatal diagnosis of congenital heart defects is often difficult and can only be carried out competently at specialist centres.

For the past 10 years there has been a centre for prenatal diagnosis and treatment at the Charité Hospital, at which approximately 3000 women with high risk pregnancies are examined annually. About 60 heart defects are detected prenatally each year, including about 20 cases that are examined postmortem (induced and spontaneous abortions and stillbirths). Congenital heart defects are often associated with extracardiac malformations. In the Baltimore-Washington Infant Study (BWIS) the frequency of associated extracardiac anomalies in live births is given as $20 \%{ }^{1}$ Some of these cases are caused by chromosome abnormalities: $4.5 \%$ of all congenital heart defects in liveborn infants are part of a complex syndrome resulting from a chromosome anomaly, ${ }^{7}$ and considerably more in embryos and fetuses, since chromosome abnormalities often lead to death at an early gestational stage. In a prenatal study published by Chaoui et al, ${ }^{8}$ $22 \%$ of the fetuses with congenital heart defects had chromosome aberrations.

Not only is the rate of chromosome aberrations significantly higher in fetuses than in liveborn infants because of their reduced viability, but so also is the spectrum of congenital heart defects, as well as their association with extracardiac malformations.

Our goal in this paper is to analyse the spectrum of congenital heart malformations, to determine the frequency of extracardiac malformations and the proportion of chromosome 
Table 1 Incidence of congenital heart defects, other cardiovascular (CV) and extracardiac malformations, and cases with chromosome anomalies (1991-97)

\begin{tabular}{|c|c|c|c|c|c|c|c|c|c|c|c|}
\hline $\begin{array}{l}\text { Diagnostic } \\
\text { group }\end{array}$ & Total & $\begin{array}{l}\text { No other CV or } \\
\text { extracardiac } \\
\text { malformations }\end{array}$ & $\begin{array}{l}\text { With other } C V \\
\text { malformations }\end{array}$ & $\begin{array}{l}\text { With } \\
\text { extracardiac } \\
\text { malformations }\end{array}$ & $\begin{array}{l}\text { Chromosome } \\
\text { anomalies }\end{array}$ & $\begin{array}{l}\text { Trisomy } \\
21\end{array}$ & $\begin{array}{l}\text { Trisomy } \\
18\end{array}$ & $\begin{array}{l}\text { Trisomy } \\
13\end{array}$ & $\begin{array}{l}\text { Monosomy } \\
X\end{array}$ & $\begin{array}{l}\text { Triploidy } \\
N\end{array}$ & $\begin{array}{l}\text { Other } \\
\text { structural } \\
\text { anomalies }\end{array}$ \\
\hline VSD & $36(28)$ & - & 20 & 31 & 15 & 8 & 4 & 1 & - & 1 & 1 \\
\hline AVSD & $21(16)$ & - & 17 & 17 & 13 & 9 & 3 & - & - & - & 1 \\
\hline HLH & $21(16)$ & $8(38)$ & 7 & 8 & 2 & - & 1 & 1 & - & - & - \\
\hline DORV & $15(12)$ & - & 14 & 11 & 5 & - & 3 & 2 & _- & _- & - \\
\hline CoA & $7(6)$ & - & 2 & 7 & 3 & 1 & - & - & 2 & - & - \\
\hline TGA & $5(4)$ & $2(40)$ & 4 & 1 & - & - & - & - & - & - & - \\
\hline AoVs & $5(4)$ & $1(20)$ & 4 & 1 & 1 & - & - & - & 1 & - & - \\
\hline TOF & $4(3)$ & - & 4 & 3 & 2 & 1 & - & 1 & - & - & - \\
\hline TAC & $4(3)$ & - & 4 & 3 & 1 & - & - & - & - & 1 & - \\
\hline $\mathrm{PaVS} / \mathrm{PaVA}$ & $4(3)$ & - & 3 & - & - & - & - & - & - & - & - \\
\hline $\mathrm{TA}$ & $4(3)$ & - & 3 & 2 & - & - & - & - & - & - & - \\
\hline SV & $2(1.5)$ & - & 2 & - & - & - & - & - & - & - & - \\
\hline ASD & $1(0.5)$ & - & 1 & 1 & 1 & - & - & 1 & - & - & - \\
\hline Total & $129(100)$ & $11(9)$ & $85(66)$ & $85(66)$ & 43 (33) & $19(15)$ & $11(9)$ & $6(5)$ & $3(2)$ & $2(1.5)$ & $2(1.5)$ \\
\hline
\end{tabular}

Values are $\mathrm{n}$ or $\mathrm{n}(\%)$.

AoVS, aortic valve stenosis; ASD; atrial septal defect; AVSD, atrioventricular septal defect; CoA, coarctation of the aorta; DORV, double outlet right ventricle; HLH, hypoplastic left heart; $\mathrm{PaVS} / \mathrm{PaVA}$, pulmonary valve stenosis/pulmonary valve atresia; SV, single ventricle; TA, tricuspid atresia; TAC, truncus arteriosus communis; TGA, transposition of the great arteries; TOF, tetralogy of Fallot; VSD; ventricular septal defect.

aberrations among the fetuses sent to the department of pathology for necropsy, and to compare our results with those of other studies. ${ }^{9} 10$

\section{Methods}

During a seven year period (1991 to 1997) necropsies were performed in the department of pathology at the Charité Medical Centre in Berlin on 815 fetuses between 11 and 41 weeks of gestation. These included 448 induced abortions (55\%), 220 spontaneous abortions (27\%), and 147 stillbirths (18\%). In 129 cases $(16 \%)$ a congenital heart defect was diagnosed (99 induced abortions, 20 spontaneous abortions, and 10 stillbirths). In all 129 cases prenatal diagnosis was carried out at the Centre for Prenatal Diagnostics and Therapy with high resolution ultrasound and a multidisciplinary approach was used.

The following equipment was used for the cardiac examinations: Toshiba SSA100A, Toshiba SSA270A (colour Doppler) (Toshiba, Tokyo, Japan), and Ultramark-9-HDI (Advanced Technology Laboratories, Bothell, Massachusetts, USA) (B image, PW-CW, and colour Doppler). In all cases fetal karyotyping was made using various fetal tissues. Prenatal cytogenetic analyses were performed on fetal cells obtained by chorion villus sampling, amniocentesis, and cordocentesis. Since 1996 molecular cytogenetic methods have been used prenatally on suspicion of deletions in the CATCH 22 region. The patients were given counselling by our multidisciplinary team. Pregnancy was terminated in case of complex cardiac anomalies or when the heart defect was associated with severe extracardiac malformations. In addition, tissue from aborted fetuses and stillbirths was investigated.

For evaluation 13 categories were established for the classification of congenital heart defects: ventricular septal defect, atrioventricular septal defect, hypoplastic left heart, double outlet right ventricle, coarctation of the aorta, transposition of the great arteries, pulmonary valve stenosis/pulmonary valve atresia, tetralogy of Fallot, aortic valve stenosis, truncus arteriosus communis, tricuspid atresia, single ventricle, and atrial septal defect (table 1), which were either isolated or combined with other cardiovascular anomalies. Hearts with more than one lesion were classified according to the more serious lesion. The frequency of extracardiac malformations and chromosomal abnormalities in cases with congenital heart defects was examined.

\section{Results}

INCIDENCE OF CONGENITAL HEART DEFECTS

A congenital heart defect was detected in 129 of the 815 fetuses examined (16\%): 99 induced abortions (22\%), 20 spontaneous abortions (9\%), and 10 stillbirths (7\%). For all 815 fetuses, prenatal ultrasound findings and the results of karyotyping were available. In $92 \%$ of the cases the prenatally diagnosed heart malformation was confirmed at necropsy examination.

In 10 cases ( $8 \%)$, necropsy showed additional cardiac anomalies that had not been identified prenatally. In two cases, a ventriculocoronary communication was diagnosed prenatally in the 17th and 18th week of gestation using transvaginal and transabdominal colour Doppler sonography. The heart preparation showed additional ventriculo-coronary and intercoronary communications. In four cases, necropsy examination showed additional coarctation of the aorta. In three cases the necropsy examination showed a retrooesophageal origin of the right subclavian artery from the descending part of the aorta. In the final case a partial anomalous pulmonary venous connection was detected at necropsy.

In eight cases prenatally diagnosed cardiac anomalies were not confirmed at necropsy (ventricular septal defect, atrioventricular septal defect, coarctation of the aorta, and hypoplastic aorta). But in all these cases the extracardiac findings which led to the termination of pregnancy were confirmed.

The following heart deformations were diagnosed at necropsy, in order of frequency: ventricular septal defect (36), atrioventricular septal defect (21), hypoplastic left heart (21), double outlet right ventricle (15), coarctation of the aorta (7), transposition of the great 
Table 2 Frequency of malformations of the systems associated with heart defects

\begin{tabular}{ll}
\hline Organ system & $\begin{array}{l}\text { Heart defect } \\
(n=129)\end{array}(\%)$ \\
\hline Central nervous system & $40(31)$ \\
Kidney, urinary tract, and genital system & $34(26)$ \\
Gastrointestinal system & $31(24)$ \\
Respiratory system & $14(11)$ \\
Skeletal system & $10(8)$ \\
\hline
\end{tabular}

arteries (5), aortic valve stenosis (5), tetralogy of Fallot (4), truncus arteriosus communis (4), pulmonary valve stenosis/pulmonary valve atresia (4), tricuspid atresia (4), single ventricle (2), and atrial septal defect (1), with only the most significant defect being given in cases with more than one defect. Ventricular septal defect, atrioventricular septal defect, hypoplastic left heart, and double outlet right ventricle made up $72 \%$ of the heart defects (table 1 ). The ratio of males (73) to females (56) was 1.3:1.

\section{ASSOCIATION WITH OTHER CARDIOVASCULAR} MALFORMATIONS

The congenital heart malformations were isolated in only 11 cases (9\%). In $66 \%$ of the cases further cardiovascular anomalies were observed. For example, ventricular septal defect occurred together with double outlet right ventricle, coarctation of the aorta, tetralogy of Fallot, tricuspid atresia, atrial septal defect, transposition of the great arteries, and truncus arteriosus communis.

\section{ASSOCIATION WITH EXTRACARDIAC}

MALFORMATIONS

The congenital heart defects were associated with extracardiac anomalies in 85 cases $(66 \%)$. The most frequent of these anomalies involved the central nervous system $(31 \%)$, the kidneys, urinary tract, and genital system $(26 \%)$, and the gastrointestinal system $(24 \%)$. Anomalies of the respiratory system (11\%) and the skeletal system (8\%) were less common (table 2).

\section{CHROMOSOMAL ABNORMALITIES}

Chromosomal abnormalities were diagnosed in 43 cases $(33 \%)$ : there were 19 fetuses with trisomy 21,11 with trisomy 18 , six with trisomy

Table 3 Chromosome anomalies detected in fetuses with isolated heart defects, with other cardiovascular $(\mathrm{CV})$ anomalies, and with extracardiac malformations

\begin{tabular}{lllll}
\hline Chromosome anomalies & All & $\begin{array}{l}\text { Isolated heart } \\
\text { defects }\end{array}$ & $\begin{array}{l}\text { With other CV } \\
\text { anomalies }\end{array}$ & $\begin{array}{l}\text { With extracardiac } \\
\text { malformations }\end{array}$ \\
\hline Trisomy 21 & $19(44)$ & 0 & $6(32)$ & $18(95)$ \\
Trisomy 18 & $11(25)$ & 0 & $8(73)$ & $11(100)$ \\
Trisomy 13 & $6(14)$ & 0 & $5(83)$ & $6(100)$ \\
Monosomy X & $3(7)$ & 0 & $2(67)$ & $3(100)$ \\
Triploidy & $2(5)$ & 0 & $2(100)$ & $2(100)$ \\
Other structural anomalies & $2(5)$ & 0 & $1(50)$ & $2(100)$ \\
Total & $43(100)$ & $0(0)$ & $24(56)$ & $42(98)$ \\
\hline
\end{tabular}

Values are $\mathrm{n}(\%)$.

*For example: facial anomalies (flat occiput and midface, epicanthic folds, small nose, low set ears), cystic hygroma, anomalies of the central nervous system (anencephaly, encephalocele, holoprosencephaly, myelomeningocele), anomalies of the genitourinary system (renal agenesis, renal multicystic dysplasia, renal fusion, hydronephrosis, cryptorchidism, dysplastic ovaries, hypospadias), anomalies of the respiratory system (pulmonary hypoplasia, pleural effusions), anomalies of the skeletal system (clinodactyly, short fingers, syndactyly, 11 ribs, short sternum, hemivertebrae), anomalies of the gastrointestinal system (duodenal atresia, imperforate anus, malrotation, hepatic fibrosis, omphalocele, diaphragmatic hernia, tracheo-oesophageal fistula), and other.
13, three with $45, \mathrm{X}$, two with triploidy, one with trisomy 22 , and one with submicroscopic deletion at 22q11.2 (table 3).

The following cardiac abnormalities were found in the chromosomally abnormal fetuses: 13 of the 21 cases of atrioventricular septal defect $(62 \%), 15$ of the 36 cases of ventricular septal defect $(42 \%)$, two of the four cases of tetralogy of Fallot, five of the 15 cases of double outlet right ventricle, three of the seven cases of coarctation of the aorta, one of the four cases of truncus arteriosus communis, one of the five cases of aortic valve stenosis, two of the 21 cases of hypoplastic left heart, and the single cases of atrial septal defect (table 1). In contrast, fetuses with transposition of the great arteries, pulmonary valve stenosis/pulmonary valve atresia, tricuspid atresia, and single ventricle had a normal karyotype. Atrioventricular septal defect was the commonest type of congenital heart defect in cases of chromosome anomaly: nine of these cases were associated with trisomy 21 , three with trisomy 18 , and one with trisomy 22 .

Trisomy 21 and trisomy 18 were more often associated with atrioventricular septal defect or ventricular septal defect than with hypoplastic left heart, double outlet right ventricle, coarctation of the aorta, or tetralogy of Fallot. Obstruction of the left ventricular outflow tract was observed in three cases of $\mathrm{X}$ monosomy $(45, \mathrm{X})$.

None of the 43 cases with chromosomal abnormalities had an isolated heart defect. In $56 \%$ of the cases the heart defects were accompanied by other cardiovascular anomalies and $98 \%$ were accompanied by extracardiac malformations.

\section{Discussion}

INCIDENCE OF CONGENITAL HEART DEFECTS

In these fetal necropsy cases there was a high incidence of severe congenital heart defects. There are two reasons for this: first, the centre for prenatal diagnosis and treatment at the Charite specialises in the detection of fetal congenital heart defects, such defects being diagnosed at a very early gestational stage (as early as the 11th or 12th week of pregnancy); second, fetuses with such defects often do not go to term.

The incidence of congenital heart defects in the 815 cases presenting for necropsy in this study was $16 \%$ (22\% of induced abortions, $9 \%$ of spontaneous abortions, and $7 \%$ of stillbirths). In contrast, for live births the frequency of congenital heart defects in various epidemiological studies has ranged between four and eight per $1000 .^{1-4}$ Necropsies on neonates (stillbirths and liveborn infants dying shortly after birth) have shown incidence rates for congenital heart defects varying between $6 \%$ and $13 \% .^{5}{ }^{11-14}$

In our present study of aborted fetuses and stillbirths, ventricular septal defect was the most common defect $(28 \%)$. In no case did it occur as an isolated lesion. In $56 \%$ it was associated with other cardiovascular anomalies (double outlet right ventricle, coarctation of the aorta, tetralogy of Fallot, tricuspid atresia, 
atrial septal defect, transposition of the great arteries, and truncus arteriosus communis), in $86 \%$ with extracardiac malformations, and in $42 \%$ with chromosome abnormalities.

Ventricular septal defect has been reported to be the most frequent cardiac defect in various other necropsy studies of live births and stillbirths, ${ }^{515}$ and in those studies the proportion was higher than in ours (between $32 \%$ and $42 \%$ ); this difference may reflect the composition of the case population, as the studies cited included not only stillbirths but also liveborn infants, among whom ventricular septal defect mainly occurs as an isolated lesion which may allow the infant to survive the first few days after birth. In prenatal ultrasound investigations by Hanna et al, ${ }^{9}$ ventricular septal defect was diagnosed in $38 \%$ of the cases $(21 / 60)$. In the Baltimore-Washington Infant Study (BWIS), ${ }^{1}$ which is a nine year (1981 to 1989) epidemiological study of congenital heart defects in 4390 live births up to the end of the first year of life, ventricular septal defect made up a higher proportion of the defects $(32 \%)$ than in the current study, with $81 \%$ of the cases occurring in isolation.

The spectrum and frequency of the individual lesions differ from those found in paediatric cardiology surveys. ${ }^{3}{ }^{16}$ Severe heart defects such as atrioventricular septal defect, hypoplastic left heart, and double outlet right ventricle, which are usually lethal, made up $44 \%$ of the malformations in our necropsy population (of which $58 \%$ were induced abortions). In one study, severe congenital heart defects diagnosed at prenatal ultrasound examinationsuch as atrioventricular septal defect, hypoplastic left heart, and tetralogy of Fallotcomprised $33 \%$ of the cases. ${ }^{9}$ In contrast, in the BWIS, atrioventricular septal defect, hypoplastic left heart, and double outlet right ventricle comprised only $13 \%$ of the cases among liveborn infants. Our results show that complex heart defects more often lead to spontaneous abortion or to stillbirths. In addition, if highly specialised prenatal diagnosis is made before viability, termination of pregnancy can be offered.

The slightly higher proportion of males with congenital heart defects in our population agrees with the results of other necropsy studies. ${ }^{5}{ }^{611-13}$

ASSOCIATION WITH OTHER CARDIOVASCULAR MALFORMATIONS

Some $66 \%$ of the fetuses with congenital heart defects had more than one defect. In published reports, ${ }^{5612}$ necropsy studies of live births and stillbirths showed that up to $52 \%$ of the cases had more than one cardiac anomaly. The proportion was higher in our population - which included cases in early fetal developmentthan in studies of stillbirths or live births, which suggests that multiple cardiovascular anomalies are responsible for early spontaneous abortions.
ASSOCIATION WITH EXTRACARDIAC MALFORMATIONS

In the present population, 85 cases $(66 \%)$ with congenital cardiac defects also had extracardiac malformations. This high proportion of extracardiac anomalies reflects the detailed ultrasonic investigations in fetuses with congenital heart defects, which in many cases led to deliberate termination of pregnancy. On the other hand, the high proportion of extracardiac malformations also reflects our comprehensive necropsy investigations, which took into account all the prenatal investigations. The most frequent extracardiac anomalies were found in the central nervous system, the kidneys, the urinary tract and the genital system, and the gastrointestinal system; malformations of the respiratory system and the skeletal system were less common (table 2).

In contrast, in the BWIS only $27 \%$ of the congenital heart defects were associated with extracardiac anomalies, the most frequent being of the central nervous system, the eyes, the gastrointestinal system, and the kidneys, urinary tract and genital system, as well as of the abdominal wall. ${ }^{17}$ It was noted in the BWIS that the majority of cases of transposition of the great arteries and right and left sided obstructive defects were not associated with extracardiac anomalies, and in our study only one case of transposition of the great arteries was associated with an extracardiac malformation. For malformations of the outflow tract, Lurie et al gave a ratio of isolated extracardiac anomalies to combined extracardiac anomalies of $1: 2.5 .^{18}$

Prenatal investigations have shown that heart defects often accompany defects in other organ systems. Copel et $a l^{19}$ and Greenwood et $a l^{2-22}$ observed heart defects in 30\% of omphaloceles, in up to $20 \%$ of cases of duodenal atresia, in up to $30 \%$ of congenital diaphragmatic hernias, in between $5 \%$ and $15 \%$ of CNS malformations, and between $8 \%$ and $71 \%$ of the cases with defects of the kidneys, urinary tract, and genital system. These findings point to the need to investigate the heart in cases of extracardiac anomaly and to look for extracardiac anomalies when cardiovascular malformations have been diagnosed.

\section{CHROMOSOME ABNORMALITIES}

In our study, chromosomal abnormalities were associated with congenital heart defects in 43 of the fetuses (33\%). Among liveborn infants with heart defects, around 5\% have chromosome abnormalities, ${ }^{23}$ the proportion being as high as $12 \%$ in more recent studies. ${ }^{1}$ Prenatal investigations by Chaoui et al showed a higher rate of chromosomal abnormalities in fetuses with congenital heart defects (22\%) than among live births. ${ }^{8}$ In an analysis of fetuses with heart defects, Gembruch et al found chromosome abnormalities in $28 \% .^{24}$ The incidence of congenital heart defects and chromosome abnormalities in fetuses is higher than in liveborn infants or stillbirths as the fetuses often do not survive until birth and are therefore not included in statistical data collected by paediatric cardiologists. ${ }^{25-27}$ In 
published reports, the frequency of chromosome abnormalities found after the discovery of a congenital heart defect varies between $16 \%{ }^{25}$ and $50 \%{ }^{28}$ In a prenatal study of fetuses with congenital heart defects by Körner et al, the rate of chromosome anomalies was found to be $29 \%$. $^{29}$

In the current study ventricular septal defect, atrioventricular septal defect, hypoplastic left heart, and double outlet right ventricle were associated with the highest rates of chromosome abnormalities, in contrast to cases with simple vascular obstruction or malformations such as pulmonary valve stenosis/pulmonary valve atresia, tricuspid atresia, and transposition of the great arteries, where there was a low prevalence of chromosome anomalies.

Among the 43 chromosomally abnormal fetuses, the following abnormalities were detected: 19 with trisomy 21,11 with trisomy 18 , six with trisomy 13, three with monosomy $\mathrm{X}$, two with triploidy, one with trisomy 22 , and one with a submicroscopic deletion at chromosome 22q11.2. Atrioventricular septal defect was associated with the highest proportion of chromosomal abnormalities: 12 of the 21 fetuses $(57 \%)$ with this defect had an aneuploidy, including nine with trisomy 21 and three with trisomy 18 . In the BWIS, trisomy 21 was the most frequent abnormality associated with congenital heart defects, followed by trisomy 18, trisomy 13, and monosomy $\mathrm{X}$ $(45, \mathrm{X})$.

In our present study the following association between chromosome abnormalities and cardiac defects was observed: $30 \%$ of cases of ventricular septal defect/atrioventricular septal defect were associated with trisomy $21 ; 12 \%$ of cases of ventricular septal defect/atrioventricular septal defect were associated with trisomy 18 ; and $29 \%$ of cases of anomaly of the aortic arch were associated with monosomy $\mathrm{X}$. In a study of fetuses in the 11 th to 16 th week of gestation, Hyett et al also detected an association between atrioventricular septal defect/ventricular septal defect and trisomy 21 , ventricular septal defect and trisomy 18 , and severe narrowing of the aortic arch and $45, \mathrm{X} .{ }^{15}$ In a retrospective study of 272 children with Down's syndrome who came to necropsy, Warkany et al found heart defects in $52 \%$ and in $64 \%$ of these the anomaly was an atrioventricular septal defect. ${ }^{30}$ In our study, seven fetuses $(47 \%)$ with prenatally diagnosed trisomy 21 also had an atrioventricular septal defect. For this reason chromosome analysis is indicated for every prenatally diagnosed heart defect. Fetuses which have not been investigated prenatally should have postnatal cytogenetic investigation. If the karyotype is normal, more detailed investigations may need to be carried out (for possible exclusion of mosaicism or microdeletion), depending on the clinical findings.

Hyett et al observed increased thickness of nuchal translucency between the 11th and the 16 th week of gestation in fetuses with trisomy 21,18 , and 13 and monosomy $\mathrm{X}(45, \mathrm{X})$ who also had an atrioventricular septal defect or a ventricular septal defect; they showed that the aortic isthmus was significantly narrower in these fetuses than in normal fetuses and postulated that this might explain the increased nuchal translucency in these four chromosome anomalies. ${ }^{15}$

Cardiac development is regulated by complex mechanisms involving interaction between genetic and environmental factors. The aetiology of the majority (70-80\%) of congenital heart defects is still unexplained. With progress in molecular and developmental biology, our understanding of factors that influence cardiac development is likely to increase. In the last few years it has been shown, for example, that conotruncal heart defects such as tetralogy of Fallot, truncus arteriosus communis, double outlet right ventricle, and transposition of the great arteries, together with various types of ventricular septal defects, are associated with a microdeletion on chromosome $22 .{ }^{31-34}$ Raymond et al have described five cases with congenital heart defects which showed a deletion of $22 \mathrm{q} 11.2$ at prenatal diagnosis. ${ }^{35}$ The incidence of $\operatorname{del}(22)$ is reported to be $1 / 5000-$ 10000 births. In 106 fetuses with congenital heart defects and a normal karyotype, Lucy et al found two cases with a $22 \mathrm{q} 11.2$ deletion. ${ }^{10}$ In cases where conventional methods showed a normal karyotype, chromosome abnormalities (7q11.23, 10p13, and $8 \mathrm{p}$ deletions) were assumed by Lucy to be the cause of the cardiac anomalies. In one of our cases with a ventricular septal defect associated with coarctation of the aorta, it was possible to detect a deletion at chromosome 22 by molecular genetic investigations. Up to now aborted fetuses have not been included in investigations of the genetic basis of heart defects. ${ }^{36}$

In 10 of our cases ( $8 \%$ ), necropsy showed additional cardiac anomalies that had not been diagnosed prenatally. In eight cases, prenatally diagnosed cardiac anomalies were not confirmed at necropsy (ventricular septal defect, atrioventricular septal defect, coarctation of the aorta, and hypoplastic aorta), but in all these cases the extracardiac findings, which led to termination were confirmed.

\section{CONCLUSIONS}

Specific prenatal ultrasound diagnosis and necropsy investigation, supported by molecular and cytogenetic investigations, can provide us with a good idea of the many factors that lead to congenital heart defects. ${ }^{37}$ In such cases systematic collection of data is necessary to provide an adequate basis for counselling families, as well as for the clinical or necropsy investigation of congenital heart defects, extracardiac malformations, and chromosomal abnormalities. Our future investigations will be devoted to the identification of the genes and modifying factors that play a role in congenital malformations of the heart, which may make it possible to estimate the risk for affected families.

\footnotetext{
1 Ferencz C, Rubin JD, Loffredo CA, et al. Epidemiology of Study 1981-1989. Mount Kisko: Futura, 1993:33-73.

2 Ferencz C, Rubin JD, McCarter RJ, et al. Congenital heart disease: prevalence at livebirth. The Baltimore-Washington Infant Study. Am f Epidemiol 1985;121:31-6.
} 
3 Hoffmann JIE, Christianson R. Congenital heart disease in a cohort of 19502 birth with long-term follow-up. Am $\mathcal{F}$
Cardiol 1978; $42: 641-7$.

4 Mitchell SC, Corones SB, Berendes HW. Congenital heart disease in 56109 births. Circulation 1971;43:323-32.

5 Samanek M, Goetzova J, Benesova D. Distribution of congenital heart malformations in an autopsied child population. Int $\mathcal{F}$ Cardiol 1985;8:235-50.

6 Tennstedt A, Gutermann M, Schreiber D. Malformations of the heart and vascular system in autopsy material of children. Z Allg Pathol Pathol Anat 1983;128:127-32.

7 Witkowski R, Prokop O, Ullrich E. Lexikon der Syndrome und Fehlbildungen: Ursachen, Genetik und Risiken. Berlin: Springer, 1995.

8 Chaoui R, Körner H, Tennstedt C, et al. Prenatal diagnostizierte Herzfehlbildungen und assoziierte Chromosomenaberrationen. Ultraschall Med 1996;17:17.

9 Hanna JS, Neu RL, Lockwood DH. Prenatal cytogenetic results from cases referred for 44 different types of abnorresults from cases referred for 44 different types of abnor-

10 Lucy RF, Mackie CM, Simpson J, et al. Incidence of 22q11 deletion and karyotype abnormalities in fetuses with cardiac abnormalities detected prenatally [abstract]. $\mathcal{F} \mathrm{Med}$ Genet 1996:33 (suppl 1):S25.

11 Laursen HB. Some epidemiological aspects of congenital heart disease in Denmark. Acta Paediatr Scand 1980;69: 619-24.

12 Goetzova J, Benesova D. Angeborene Herzfehler im Sektionsmaterial totgeborener und verstorbener Kinder im mittelböhmischen Bezirk in den Jahren 1967-1976. Cesk Pediatr 1979;34:547-50.

13 Jaiyesimi F, Antia AU. Extracardiac defects in children with congenital heart disease. Br Heart 7 1979;42:475-9.

14 Schultrich S. Die angeborenen Herzfehler im Sektionsmaterial des Pathologischen Universitätsinstituts Leipzig. $Z$ Allg Pathol Pathol Anat 1977;121:429-39.

15 Hyett J, Moscoso G, Nicolaides K. Abnormalities of the heart and great arteries in first trimester chromosomally heart and great arteries in first trimester chromos

16 Allan LD, Crawford DC, Anderson RH, et al. Spectrum of congenital heart disease detected echocardiographically in prenatal life. Br Heart $\mathcal{F}$ 1985;54:523-6.

17 Ferencz C, Rubin JD, McCarter RJ, et al. Cardiac and noncardiac malformations: observation in a population-based study. Teratology 1987;35:367-78.

18 Lurie IW, Kappetein AP, Loffredo CA, et al. Non-cardiac malformations in individuals with outflow tract defects of the heart: the Baltimore-Washington Infant Study (19811989). Am F Med Genet 1995;59:76-84.

19 Copel JA, Pilu G, Kleinmann C. Congenital heart disease and extracardiac anomalies; associations and indications for fetal echocardiography. Am f Obstet Gynecol 1986;154: $1121-32$

20 Greenwood RD, Rosenthal A, Nadas AS. Cardiovascular anomalies associated with congenital anomalies of the urinary system. Clin Pediatr 1974;15:1101-14.
21 Greenwood RD, Rosenthal A, Nadas AS. Cardiovascular abnormalities associated with congenital diaphragmatic hernia. Pediatrics 1976;57:92-7.

22 Greenwood RD, Rosenthal A, Parisi L, et al. Extracardiac abnormalities in infants with congenital heart disease. Pediatrics 1975;55:485-92.

23 Keck EW. Kardiolgie. Neugeborene, Kinder, Säuglinge, 4th ed. Munich: Urban and Schwarzenberg, 1989.

24 Gembruch U, Bald R, Redel D, et al. Bedeutung der pränatalen Diagnostik angeborener Herzfehler. In: Fahrbuch der Gynäkologie und Geburtshilfe. Munich: Biermann-Verlag, 1991:107-18.

25 Allan LD, Sharland GK, Chita SC, et al. Chromosomal anomalies in fetal congenital heart disease. Ultrasound Obstet Gynecol 1991;1:8-11.

26 Allan LD, Sharland GK, Milburn A, et al. Prospective diagnosis of 1006 consecutive cases of congenital heart disease in the fetus. F Am Coll Cardiol 1994;23:1452-8.

27 Copel JA, Cullen M, Green J, et al. The frequency of aneuploidy in prenatally diagnosed congenital heart disease: an indication for fetal karyotyping. Am f Obstet Gynecol 1988; 158:409-13.

28 Paladini D, Calabro R, Palmieri S, et al. Prenatal diagnosis of congenital heart disease and fetal karyotyping. Obstet Gynecol 1993;181:679-82.

29 Körner H, Bommer CH, Chaoui R, et al. Karyotype findings in fetuses with cardiac abnormalities detected prenatally. Med Genet 1997;9(suppl 1):65.

30 Warkany J, Passarge E, Smith LB. Congenital malformations in autosomal trisomy syndromes. $A m \mathcal{F}$ Dis Child 1966;112:502-17.

31 Momma K, Kondo C, Matsuoka R. Tetralogy of Fallot with pulmonary atresia associated with chromosome 22q11 deletion. F Am Coll Cardiol 1996;27:198-202.

32 Driscoll DA. Genetic basis of DiGeorge and velocardiofacial syndromes. Curr Opin Pediatr 1994;6:702-6.

33 Matsuoka R, Takao A, Kimura M, et al. Confirmation that the conotruncal anomaly face syndrome is associated with a deletion within 22q11.2. Am f Med Genet 1994;53:285-9.

34 Seaver LH, Pierpont JW, Erickson RP, et al. Pulmonary atresia associated with maternal 22q11.2 deletion: possible parent of origin effect in the conotruncal anomaly face syndrome. F Med Genet 1994;31:830-4.

35 Raymond FL, Simpson JM, Mackie CM, et al. Prenatal diagnosis of 22q11 deletions: a series of five cases with congenital heart defects. F Med Genet 1997;34:679-82.

36 Debrus S, De Meeus A, Jean MK, et al. Genetics of hereditary cardiopathies. Arch Mal Coeur Vaiss 1996;89: 619-27.

37 Payne RM, Johnson MC, Grant JW, et al. Toward a molecular understanding of congenital heart disease. Circulation 1995;91:494-504 